\title{
EFFECTS OF DIFFERENT FERTILISATION TECHNOLOGIES AND CULTIVATION TECHNOLOGY ON SOIL ORGANIC CARBON CONTENT
}

\author{
LIU, T. \\ College of Economics and Management, Nanjing Agricultural University, Nanjing 210095, China \\ (e-mail:ysghge@163.com)
}

(Received 27 $7^{\text {th }}$ Sep 2018; accepted $16^{\text {th }}$ Jul 2019)

\begin{abstract}
Due to the different stability of organic carbon with different protection mechanisms, the response and evolution of organic carbon components of yellow loam paddy soil to long-term fertilization was studied. Our aim was to study the effects of organic carbon on soil fertility from two aspects: fertilization treatment protection mechanism and tillage treatment protection mechanism. The long-term test site is located in an agricultural science research institute in a certain province of China. The fitting analysis found that the content of soil organic carbon and its components increased with time between 2006 and 2014 under the four fertilization protection mechanisms. Except for biochemical protection of organic carbon, the linear increase of the remaining components of organic carbon is more obvious than that of single fertilizer (NPK) treatment. Compared with traditional tillage treatment, the organic carbon contents have increased by $22.9 \%$ and $21.8 \%$ respectively, and the organic carbon reserves have increased by $21.8 \%$ and $16.7 \%$, respectively. The carbon sequestration rates are 0.09 and $0.06 \mathrm{~T} \mathrm{C} \cdot \mathrm{hm}^{-2} \cdot \mathrm{a}^{-1}$. Unprotected free organic carbon is the largest part of organic carbon in soil, and is most sensitive to fertilization.
\end{abstract}

Keywords: protection mechanism; organic matter, soil fertility, yellow soil, physical protection, chemical protection, biochemical protection

\section{Introduction}

Soil organic carbon is one of the most active carbon pools in the Earth's surface system, and it plays the important role in regulating the physical, chemical and biochemical processes of soil. It is not only the indicator for assessing soil fertility, but also the important part of the global carbon cycle. Organic carbon with different protection mechanisms has different bioavailability and fertility effects (Herencia and Maqueda, 2016). The scientific basis for the assessment of soil carbon sequestration potential in farmland soils in Southwest China is provided by studying the changes in organic carbon composition of different protective mechanisms of yellow paddy soil with long-term fertilization (Ouyang et al., 2017; Wang et al., 2016; Zhang et al., 2015).

Kang Rifeng's analysis of long-term monitoring data of 17 national arable land in the black soil region of Northeast China shows that after 10-26 years of evolution, the organic matter content has increased overall, which is $33.9 \%$ higher than that before monitoring (Kintché et al., 2015). Hu Mingfang studied the evolution of soil organic carbon in double-crop paddy fields in Poyang Lake area under long-term fertilization (Kunlanit et al., 2014). The results show that the carbon content increases with the fertilization period under organic fertilizer treatment, which is consistent with $\mathrm{Xu}$ Minggang's research on the law of change of soil organic matter. The organic carbon reserves of $0-20 \mathrm{~cm}$ ploughed layer estimated by GATTINGER show that the cumulative rate of SOC (Soil organic carbon) is $0.24-0.46 \mathrm{t} \bullet \mathrm{hm}^{-2} \cdot \mathrm{a}^{-1}$. The evolution characteristics of organic carbon components in grey desert soils under different fertilization models analyzed by Li Sheng ( $\mathrm{Li}$ et al., 2016) shows that the organic 
carbon components show the significant increase trend under the long-term application of organic and inorganic fertilizers. In view of this, in accordance with the different solid-state mechanisms of organic carbon, the physical-chemical joint grouping method is proposed by the STEWART team to separate organic carbon into components of various protection mechanisms such as physical, chemical and biochemical protection. The role of soil micro-aggregates and minerals in the sequestration and transformation of organic carbon is emphasized, which provides the advanced method for the research on the changing characteristics of organic carbon and the transformation process.

At present, the research on the evolution characteristics of SOC under long-term fertilization mainly focuses on surface soil and particulate organic carbon, and has insufficient connection with SOC stability mechanism (Cruz Campas et al., 2017; Manjunatha et al., 2018). The differences and evolution characteristics of SOC components of different protection mechanisms are rarely noticed. Based on the previous work, the evolution characteristics of different stable organic carbons in time series are further revealed in this paper to explore their future trends.

As a sustainable agricultural technology, conservation tillage has far-reaching implications for improving soil fertility and carbon sequestration. SOC is the core material of soil nutrient cycling and fertility supply. The evolution law of the soil can reflect the difference of management measures. However, due to the obvious difference in carbon sequestration ability of different micro-aggregates in soil, the study on the evolution law of organic carbon is very important. At present, the research on farmland organic carbon at home and abroad mainly focuses on the protection mechanism of different tillage treatments (Amelian et al., 2018; Hu et al., 2017). The research on the law of soil organic carbon under the long-term tillage treatment protection mechanism needs to be strengthened.

Combined with long-term localization experiments and laboratory analysis, the physical-chemical of SOC combined grouping method is used to determine the content and distribution of unprotected organic carbon of free active, chemical protection and biochemically protection between micro-aggregates, and to analyze the role of soil micro-aggregates and mineral combinations in SOC sequestration and transformation. The change rate of organic carbon in yellow paddy soil with fertilization time and the effective of fertilization on improving SOC pool under different protection mechanisms are elucidated. At the same time, the carbon input and soil carbon sequestration of farmland under different tillage treatment mechanisms are analyzed, and the effects of long-term farming on the carbon reserves of $0-10 \mathrm{~cm}$ soil layer in farmland soil are discussed, these provide the reference for the improvement of soil fertility and the choice of carbon sequestration technology on the Loess Plateau.

\section{Materials and methods}

\section{The general situation of the research area}

The long-term test site is located in an agricultural science research institute in a certain province of China (106 $\left.39^{\prime} 52^{\prime \prime} \mathrm{E}, 26^{\circ} 29^{\prime} 49^{\prime} \mathrm{N}\right)$. It is located in the hilly area of central Guizhou and has the subtropical monsoon climate with the average elevation of $1071 \mathrm{~m}$ and the average annual temperature of $15.3{ }^{\circ} \mathrm{C}$, the annual average sunshine hours is about $1354 \mathrm{~h}$, the relative humidity is $75.5 \%$, the annual frost-free period is about $270 \mathrm{~d}$, and the annual precipitation is $1100-1200 \mathrm{~mm}$. The test site is yellow loess paddy soil, and the parent material is triassic limestone and sand shale weathering. It 
began in 1995. In 1994, the basic soil samples were collected. The soil properties of the cultivated layer $(0-20 \mathrm{~cm})$ are: organic matter $31.15 \mathrm{~g} \bullet \mathrm{kg}^{-1}$, total nitrogen $1.76 \mathrm{~g} \bullet \mathrm{kg}^{-1}$, total potassium $13.84 \mathrm{~g} \cdot \mathrm{kg}^{-1}$, alkali nitrogen $134.4 \mathrm{mg} \cdot \mathrm{kg}^{-1}$, available phosphorus $21.1 \mathrm{mg} \bullet \mathrm{kg}^{-1}$, available potassium $157.9 \mathrm{mg} \cdot \mathrm{kg}^{-1}$, and $\mathrm{pH}$ 6.6.

\section{Methods}

\section{Experimental design}

\section{(1) Fertilization treatment}

A ploughing field is selected as the experimental field. Before the experiment, the ploughing layer soil $(0-20 \mathrm{~cm})$ had a $\mathrm{pH}$ value of $8.70-9.10$, and the conductivity is $0.362-0.702 \mathrm{dS} / \mathrm{m}$, the mass fraction of organic carbon is $3.10-4.70 \mathrm{~g} / \mathrm{kg}$, the mass fraction of total nitrogen is $250-400 \mathrm{mg} / \mathrm{kg}$, the mass fraction of organic phosphorus is $3.0-7.0 \mathrm{mg} / \mathrm{kg}$, and the mass fraction of available potassium is $110.23 \mathrm{mg} / \mathrm{kg}$. According to the needs, 5 fertilization treatments are selected from 11 treatment methods (Roy et al., 2018): control (CK), single application of chemical fertilizer (NPK), single application of organic fertilizer (M), low-level organic and inorganic fertilizer application (0.5MNPK) and the high amount of organic and inorganic fertilizers (MNPK) (Naab et al., 2015). The test uses the large-area comparison test with a plot area of $201 \mathrm{~m}^{2}(35.7 \mathrm{~m} * 5.6 \mathrm{~m})$ without repetition. The type of the applied organic fertiliser is: The chemical fertilizer is urea (including $\mathrm{N} 46 \%$ ), superphosphate (including $\mathrm{P}_{2} \mathrm{O}_{5} 16 \%$ ), potassium chloride (including $\mathrm{K}_{2} \mathrm{O} 60 \%$ ); organic fertilizer contains C $413.8 \mathrm{~g} \bullet \mathrm{kg}^{-1}, \mathrm{~N} 2.7 \mathrm{~g} \bullet \mathrm{kg}^{-1}, \mathrm{P}_{2} \mathrm{O}_{5} 1.3 \mathrm{~g} \bullet \mathrm{kg}^{-1}, \mathrm{~K}_{2} \mathrm{O} 6.0 \mathrm{~g} \bullet \mathrm{kg}^{-1}$. The NPK treatment method is applied annually with $\mathrm{N} 165 \mathrm{~kg} \cdot \mathrm{hm}^{-2}, \mathrm{P}_{2} \mathrm{O}_{5} 82.5 \mathrm{~kg} \cdot \mathrm{hm}^{-2}, \mathrm{~K}_{2} \mathrm{O}$ $82.5 \mathrm{~kg} \cdot \mathrm{hm}^{-2}$, the annual application of organic fertilizer in the $\mathrm{M}$ treatment is $61.1 \mathrm{t} \cdot \mathrm{hm}^{-2}$; the amount of fertilizer applied by MNPK is the amount of fertilizer applied by M treatment plus NPK treatment. The amount of nitrogen applied by NPK treatment, $\mathrm{M}$ treatment, and 0.5MNPK treatment was the same (Qiu et al., 2014). The application amount of chemical nitrogen fertilizer is adjusted according to the nutrient content of organic fertilizer every year, as shown in Table 1. From 2002 to 2006, due to the destruction of the irrigation facilities at the test base, rice cultivation could not be satisfied and corn is replanted. The rice varieties planted are as follows: Jinma Stick (1995-1998), Nonghuhe (1999-2001), Xiangliangyou 875 (2007-2008), Yanyou United No. 2 (2009) and Maoyou 601 (2010-2014).

\section{(2) Tillage treatment}

The trial began in 1999 and the crop planted in the plot is rice. There are 4 treatments and 3 repetitions (Zhang et al., 2016). RT: When the rice is harvested, leave $10 \mathrm{~cm}$, the straw and rice ears are taken away, and the soil is ploughed $20 \mathrm{~cm}$ after harvesting, and then simmered; NT: When the rice is harvested, leave $30 \mathrm{~cm}$, and the remaining straw is threshed and left in the ground; SM: When the rice is harvested, leave $30 \mathrm{~cm}$, and the remaining straw will be left in the ground after threshing. The soil will be separated by $60 \mathrm{~cm}$ and ploughed $30-35 \mathrm{~cm}$ after harvesting. CT: When rice is harvested, it leaves $10 \mathrm{~cm}$, and the straw and rice ears are taken away. After harvesting, the soil is ploughed by $20 \mathrm{~cm}$. Carry out the second ploughing, fertilize, simmer, and sow before planting. The fertilization amount of each treatment is $\mathrm{N} 150 \mathrm{~kg} \cdot \mathrm{hm}^{-2}, \mathrm{P}_{2} \mathrm{O}_{5} 105 \mathrm{~kg} \cdot \mathrm{hm}^{-2}$, and $\mathrm{K}_{2} \mathrm{O} 45 \mathrm{~kg} \bullet \mathrm{hm}^{-2}$. 
Table 1. Annual amount of pure nutrient treatment in each treatment

\begin{tabular}{|c|c|c|c|c|}
\hline Handle & $\begin{array}{c}\text { Stable manure } \\
\qquad\left(\mathbf{t} \cdot \mathbf{h m}^{-2}\right)\end{array}$ & $\begin{array}{c}\mathrm{N} \\
\left(\mathbf{k g} \cdot \mathbf{h m}^{-2}\right)\end{array}$ & $\begin{array}{c}\mathrm{P}_{2} \mathrm{O}_{5} \\
\left(\mathrm{~kg} \cdot \mathrm{hm}^{-2}\right)\end{array}$ & $\begin{array}{c}\mathrm{K}_{2} \mathrm{O} \\
\left(\mathrm{kg}^{\prime} \mathbf{h m}^{-2}\right)\end{array}$ \\
\hline CK & 0 & 0 & 0 & 0 \\
\hline NPK & 0 & 165 & 82.5 & 82.5 \\
\hline $0.5 \mathrm{MNPK}$ & 30.6 & 165 & 81 & 224.6 \\
\hline $\mathrm{M}$ & 61.1 & 165 & 79.4 & 366.6 \\
\hline MNPK & 61.1 & 330 & 161.9 & 449.1 \\
\hline
\end{tabular}

\section{Collection of samples}

Soil samples of 0-20 cm of ploughed soil in each district are collected in October 2014. The zones are equally divided into 3 plots $\left(67 \mathrm{~m}^{2}\right)$, and each plot is uniformly distributed to collect 5 points to form the mixed sample, and 3 soil samples are collected from each plot. After removing the animal and plant residues, mix them. After the soil sample is air-dried, pass through the sieve with the pore size of $2 \mathrm{~mm}$ and set aside. The same method is used to collect soil samples for 2006, 2008, 2010 and 2012. They are air dried and sealed in the ziplock bag.

\section{SOC grouping and measuring method}

By referring to STEWART and other methods, SOC is divided into four carbon pools, which are free active organic carbon, physically protected organic carbon, chemically protected organic carbon and biochemically protected organic carbon (Wang et al., 2014). The specific operation steps are as follows.

The first step is to group the micro-aggregates: air dried soil samples over the $2 \mathrm{~mm}$ sieve are placed in the microaggregate separator and 30 glass beads having the diameter of $4 \mathrm{~mm}$ are added. After the separator is operated for $20 \mathrm{~min}$, the component remaining on the $250 \mu \mathrm{m}$ sieve is coarse particulate organic matter, and the free colloidal particles could pass through the $53 \mu \mathrm{m}$ sieve. They are then centrifuged at $900 \mathrm{r} / \mathrm{min}$ and $3200 \mathrm{r} / \mathrm{min}$ for $7 \mathrm{~min}$ and $15 \mathrm{~min}$, respectively, and d-Silt and d-C lay are obtained, respectively.

The second step is density grouping: the microaggregate fraction obtained in the first step is floated by $1.70 \mathrm{~g} \cdot \mathrm{cm}^{-3}$ of sodium iodide, and the float is fine particulate organic matter. The recombinant part is dispersed in $5 \mathrm{~g} \cdot \mathrm{L}^{-1}$ six sodium polyphosphate solution for $18 \mathrm{~h}$, passed through the $53 \mu \mathrm{m}$ sieve, and left on the sieve as physical protective organic matter. The particles smaller than $53 \mu \mathrm{m}$ are then separated by centrifugation to obtain $\mu$-Silt and $\mu$-Clay.

The third step is the acid hydrolysis process: all the particles and cosmid fractions are refluxed for $16 \mathrm{~h}$ in $6 \mathrm{~mol} \cdot \mathrm{L}^{-1} \mathrm{HCl}$ at $95{ }^{\circ} \mathrm{C}$ less than $25 \mathrm{~mL}$. The acid hydrolysis solution is filtered off, and the residue is the biochemical protective organic component (NH-Silt and NH-C lay). The acidolysis moiety is the difference between the full component and the non-acidolytic component, namely the chemically protected organic component (H-Silt and H-Clay).

The elemental analyzer (Lehman, EA3000) is used to determine the carbon content. 


\section{Calculation method}

(1) Organic carbon reserve and micro-aggregate organic carbon reserve:

$$
M_{\text {soil }}=S O C \times B D \times H \times 10^{-1}
$$

where $M_{\text {soil }}$ is the SOC reserve of $0-10 \mathrm{~cm}$ layer $\left(\mathrm{t} \mathrm{C} \cdot \mathrm{hm}^{-2}\right) ; B D$ is the soil bulk density of $0-10 \mathrm{~cm}\left(\mathrm{~g} \bullet \mathrm{cm}^{-3}\right) ; H$ is the thickness of the soil layer, $10 \mathrm{~cm}$;

$$
M_{i}^{\prime}=C_{i} \times S O C_{i} \times B D \times H \times 10^{-1}
$$

where $M_{i}^{\prime}$ is organic carbon reserves of i-level micro-aggregates $\left(\mathrm{t} \mathrm{C} \cdot \mathrm{hm}^{-2}\right) ; C_{i}$ is the relative mass fraction of the $\mathrm{i}$-th micro-aggregates; $S O C_{i}$ is the organic carbon content of the i-level micro-aggregates $\left(\mathrm{g} \bullet \mathrm{kg}^{-1}\right)$.

(2) The amount of straw carbon returned to the field and the amount of roots carbon returned to the field:

$$
Y_{\text {straw }}=Y_{\text {grain }} \times \rho
$$

where $Y_{\text {straw }}$ is straw yield $(\mathrm{t} \bullet \mathrm{hm}-2) ; Y_{\text {grain }}$ is measured grain yield $(\mathrm{t} \bullet \mathrm{hm}-2) ; \rho$ is is straw grain ratio, taken 1.1 .

$$
\text { Input }-C_{\text {straw }}=\text { Input }-Y_{\text {straw }} \times C_{\text {straw }}
$$

where Input $-C_{\text {straw }}$ is the amount of straw carbon returned to the field Input $-Y_{\text {straw }}$ is The amount of straw returned to the field. No-tillage and deep pine treatment are $100 \%$ of the yield, less tillage tradition and two sorghums is only $15 \%$ of the yield, and $C_{\text {straw }}$ is the carbon content of the straw, which is $40 \%$.

$$
Y_{\text {root }}=\left(Y_{\text {straw }}+Y_{\text {grain }}\right) \times \alpha \times \beta
$$

where $\alpha$ is the ratio of root to shoot, which is the ratio obtained after root exudates, and which is $0.6 ; \beta$ is the rate of returning to the roots, and the rate of returning the roots of $0-10 \mathrm{~cm}$ soil layer is $70 \%$.

$$
\text { Input }-C_{\text {root }}=\text { Input }-Y_{\text {root }} \times C_{\text {root }}
$$

where $C_{\text {root }}$ is the carbon content of the roots, which is $40 \%$.

\section{Data analyses}

Data collation and mapping are performed using Excel 2016, and statistical analysis is performed using SPSS 24.0. All soil measurements are expressed as the average of 3 measurements. The least significant difference method (LSD) is used to test for differences between different fertilization treatments $(P<0.05)$ (Wentzel et al., 2015). 
The average annual rate of change is expressed by the slope of the equation. The linear function is used to fit the relationship between the total organic matter and its components in the soil and the times of fertilization, and to test the significance of the equation.

\section{Experiment analyses}

From 2006 to 2014, the changes of soil organic carbon in the original yellow soil paddy soil are shown in Figure 1. Under the condition of long-term fertilizer, the changes of soil organic carbon components in yellow soil paddy soil are shown in Figure 2. According to the statistical results of Figure 2, the ratio of soil organic carbon to total organic carbon under long-term fertilizer conditions (5-year average) is given, as shown in Figure 3. Figure 4 shows the increasing trend of total soil organic carbon content under long-term fertilizer conditions.

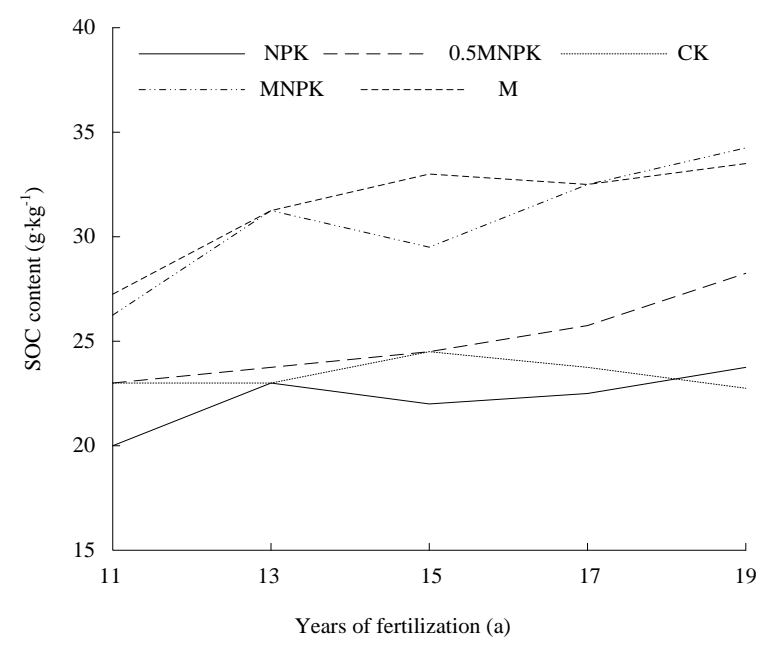

Figure 1. Changes of soil organic carbon in yellow soil paddy soil from 2006 to 2014

It can be seen from Figurel that the total organic matter content of the soil with 19 organic fertilizer is significantly higher than that of single fertilizer treatment and no fertilizer treatment, and the total organic matter is increased by $15-39 \%$, and the increase of constant organic-inorganic application is the highest. Fitting analysis find that between 2006 and 2014, the SOC content of the four fertilization treatments increased with time, and the increasing trend of organic fertilizer treatment is more obvious than that of single fertilizer application. The annual average rate of increase of total organic matter content treated with organic fertilizer is 1.5-1.6 times and 3.5-3.7 times that of non-fertilizer and single-fertilizer treatment, respectively. This indicates that long-term application of organic fertilizer can significantly increase soil organic carbon content. In order to further verify this result, the annual growth rate of the total amount of organic carbon and its components in the paddy soil of yellow soil was calculated, as shown in Table 2.

It can be known from the results in Table 2 that long-term application of organic fertilizer does increase the soil organic carbon content and can effectively increase rice yield. 
Table 2. Annual growth rate of total organic carbon and its components in yellow soil paddy soil from 2006 to 2014 under long-term fertilization

\begin{tabular}{c|c|c|c|c|c}
\hline Treatment & CK & NPK & M & 0.5MNPK & MNPK \\
\hline SOC & 0.17 & 0.39 & 0.62 & $0.59 * *$ & $0.61^{*}$ \\
Unprotected C & -0.02 & 0.25 & 0.38 & $0.33^{* *}$ & 0.47 \\
Physically protected C & 0.02 & 0.02 & $0.08^{* *}$ & $0.07 * *$ & $0.09^{*}$ \\
Chemically protected C & 0.01 & 0.00 & $0.10^{*}$ & 0.07 & $0.17 *$ \\
Biochemically protected C & 0.12 & $0.13^{*}$ & 0.15 & $0.12^{*}$ & 0.09 \\
\hline
\end{tabular}

$*, * *$, respectively, indicated that the fitted linear equation reached a significant level $(P<0.05)$ and a very significant level $(P<0.01)$

It can be seen from Figure 2 that compared with no fertilizer application and single application of chemical fertilizer, the application of organic fertilizer significantly increased the soil free activity, physical protection and chemical protection organic carbon content $(P<0.05)$, and the increase amount is $18-61 \%, 30-44 \%$ and $27-56 \%$. Among them, the increase of the organic-inorganic fertilization with the constant is the highest. In general, it can be seen that long-term non-fertilization and single-fertilizer treatment cannot maintain the turnover of the organic carbon pool, which is more detrimental to the accumulation of SOC components.

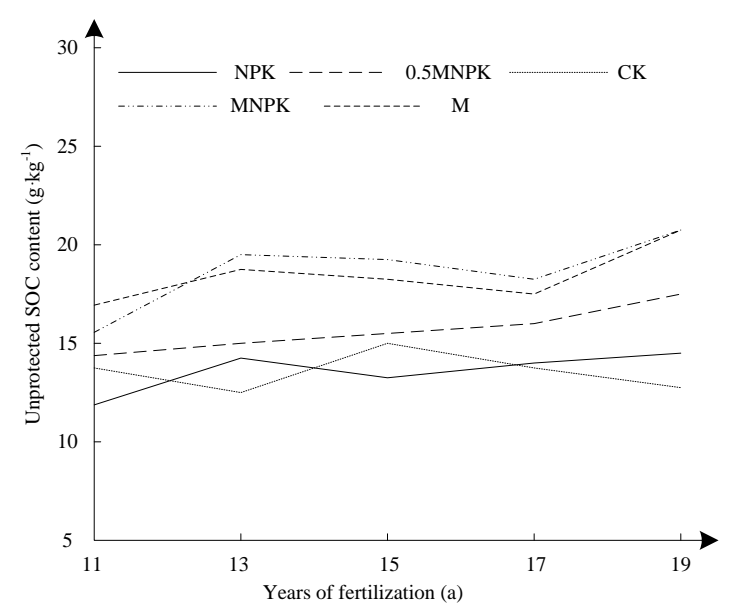

(a) Unprotected SOC content

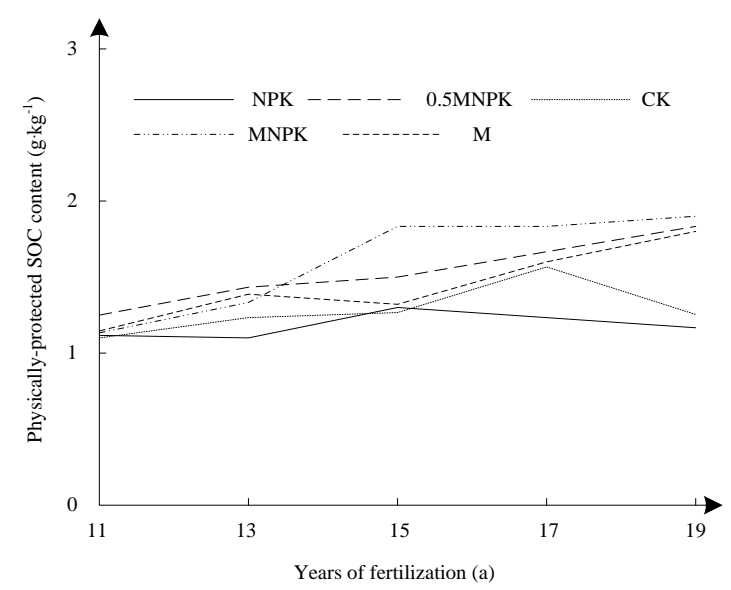

(b) Physically-protected SOC content 


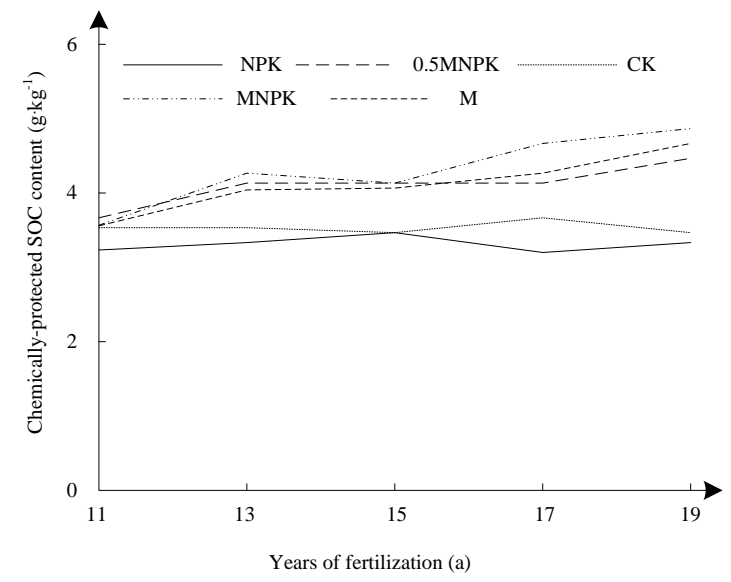

(c) Chemically-protected SOC content

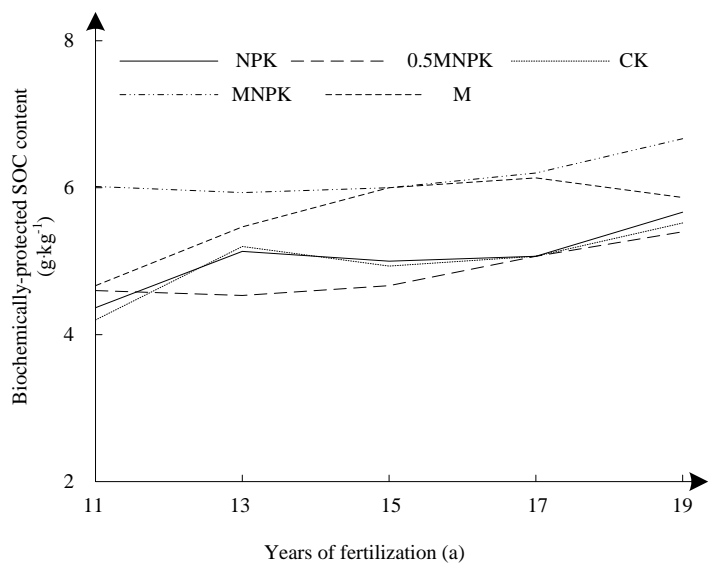

(d) Biochemically-protected SOC content

Figure 2. Changes of soil organic carbon fractions in yellow soil paddy soil during 2006 to 2014 under long-term fertilization

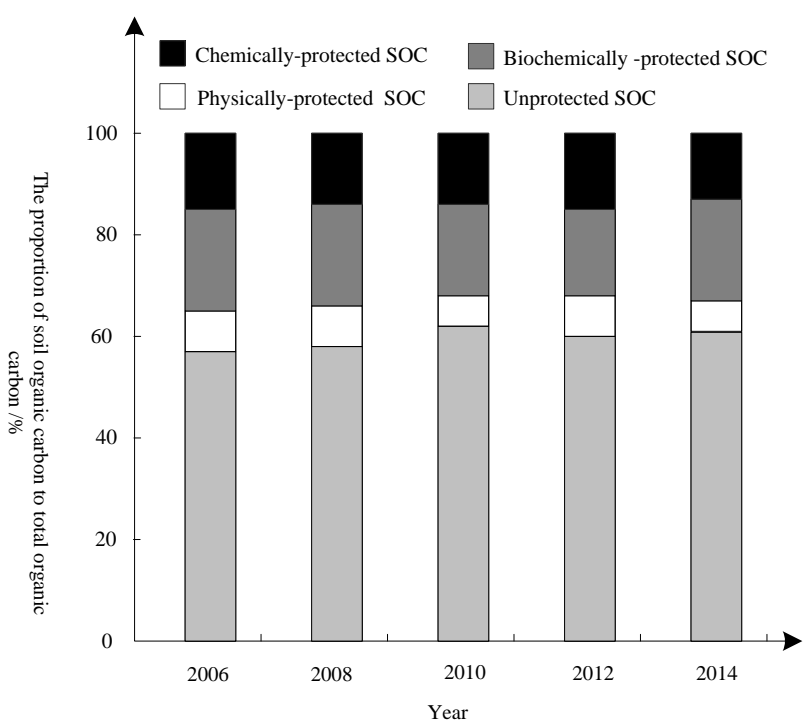

Figure 3. The proportion of soil organic carbon to total organic carbon (average value of 5 years) under long-term fertilization 
It can be seen that the difference in the ratio of organic carbon between the NPK treatment and the $\mathrm{CK}$ treatment is not obvious. In contrast, the ratio of organic fertilizer treatment is higher, and the ratio of the other two organic carbons is lower.

It can be seen from Figure 4 that except for CK treatment, the SOC content and the fertilization time in other cases show the very significant linear positive correlation $(P<$ $0.01)$. The SOC content under CK treatment increased by $3.7 \%$ compared with that in 2006; the annual growth rate of SOC content under chemical fertilizer treatment is $23.9 \%$ and $20.6 \%$.

The annual growth rate of SOC content under organic fertilizer treatment is higher, ranging from 20.6 to $21.3 \%$. This indicates that long-term application of organic fertilizer can significantly increase the SOC content.

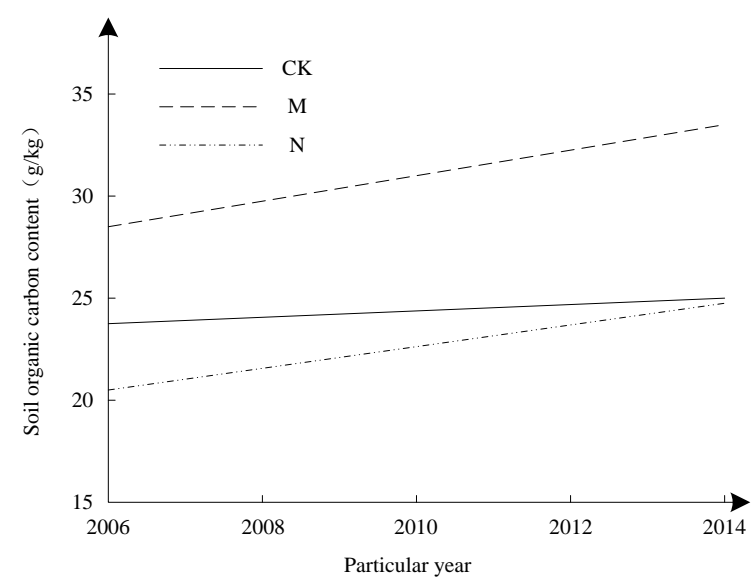

(a)

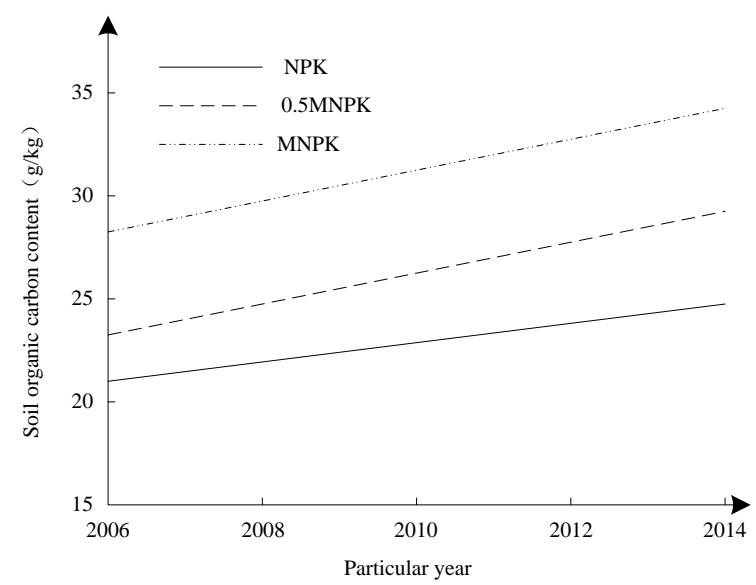

(b)

Figure 4. Growth trend of soil organic carbon content in yellow soil paddy field from 2006 to 2014 under long-term fertilization $(n=15)$

It can be seen from Table 3 that the effects of different fertilization treatments on soil carbon- $\mathrm{N}$ ratio are not significant. This indicates that the conversion relationship of soil carbon- $\mathrm{N}$ under various management measures tends to be stable with the change of fertilization years. It can be seen from the experiment that the soil carbon-N ratio of each fertilization treatment in 2006 is significantly higher than that of other years, 
indicating that land use patterns and farmland management changes can quickly affect the soil carbon- $\mathrm{N}$ ratio and quickly reach a new equilibrium. The general study suggests that the carbon-N ratio of dry-land is lower than that of paddy fields, but this study is different, and the reasons for further research are needed.

Table 3. Soil carbon and nitrogen ratio in paddy fields under long-term fertilization $\left(\mathrm{g} / \mathrm{kg}^{-1}\right)$

\begin{tabular}{c|c|c|c|c|c|c|c|c}
\hline $\begin{array}{c}\text { Soil carbon and } \\
\text { nitrogen ratio }\end{array}$ & $\mathbf{C K}$ & $\mathbf{M}$ & $\mathbf{N}$ & $\mathbf{N P K}$ & $\mathbf{0 . 5 M N P K}$ & $\mathbf{M N P K}$ & $\begin{array}{c}\text { Average } \\
\text { value }\end{array}$ & $\begin{array}{c}\text { Standard } \\
\text { deviation }\end{array}$ \\
\hline 1995 year & $11.7 \mathrm{a}$ & $11.7 \mathrm{a}$ & $11.8 \mathrm{a}$ & $11.9 \mathrm{a}$ & $11.1 \mathrm{~b}$ & $9.6 \mathrm{c}$ & 11.3 & 0.9 \\
1996 year & $14.7 \mathrm{a}$ & $10.5 \mathrm{~d}$ & $11.4 \mathrm{c}$ & $10.8 \mathrm{~cd}$ & $11.4 \mathrm{c}$ & $12.2 \mathrm{~b}$ & 11.8 & 1.5 \\
2006 year & $12.0 \mathrm{~d}$ & $18.2 \mathrm{a}$ & $12.0 \mathrm{~d}$ & $15.2 \mathrm{~b}$ & $13.3 \mathrm{c}$ & $15.4 \mathrm{~b}$ & 14.3 & 2.4 \\
2008 year & $11.8 \mathrm{~b}$ & $11.7 \mathrm{~b}$ & $10.1 \mathrm{c}$ & $13.3 \mathrm{a}$ & $10.5 \mathrm{c}$ & $12.6 \mathrm{ab}$ & 11.7 & 1.2 \\
2010 year & $10.5 \mathrm{~b}$ & $12.5 \mathrm{a}$ & $9.3 \mathrm{c}$ & $12.5 \mathrm{a}$ & $11.0 \mathrm{~b}$ & $12.0 \mathrm{a}$ & 11.3 & 1.3 \\
2012 year & $13.0 \mathrm{a}$ & $12.6 \mathrm{~b}$ & $11.8 \mathrm{~cd}$ & $12.0 \mathrm{c}$ & $11.5 \mathrm{~d}$ & $11.8 \mathrm{~cd}$ & 12.1 & 0.6 \\
2014 year & $12.3 \mathrm{a}$ & $12.1 \mathrm{a}$ & $12.6 \mathrm{a}$ & $12.6 \mathrm{a}$ & $11.9 \mathrm{a}$ & $12.1 \mathrm{a}$ & 12.3 & 0.3 \\
Average value & 12.3 & 12.8 & 11.3 & 12.6 & 11.5 & 12.2 & & \\
Standard deviation & 1.3 & 2.5 & 1.2 & 1.4 & 0.9 & 1.7 & & \\
\hline
\end{tabular}

According to the analysis of Figure 5, there is no significant difference in soil bulk density of 0-10 cm layer in different long-term cultivation.
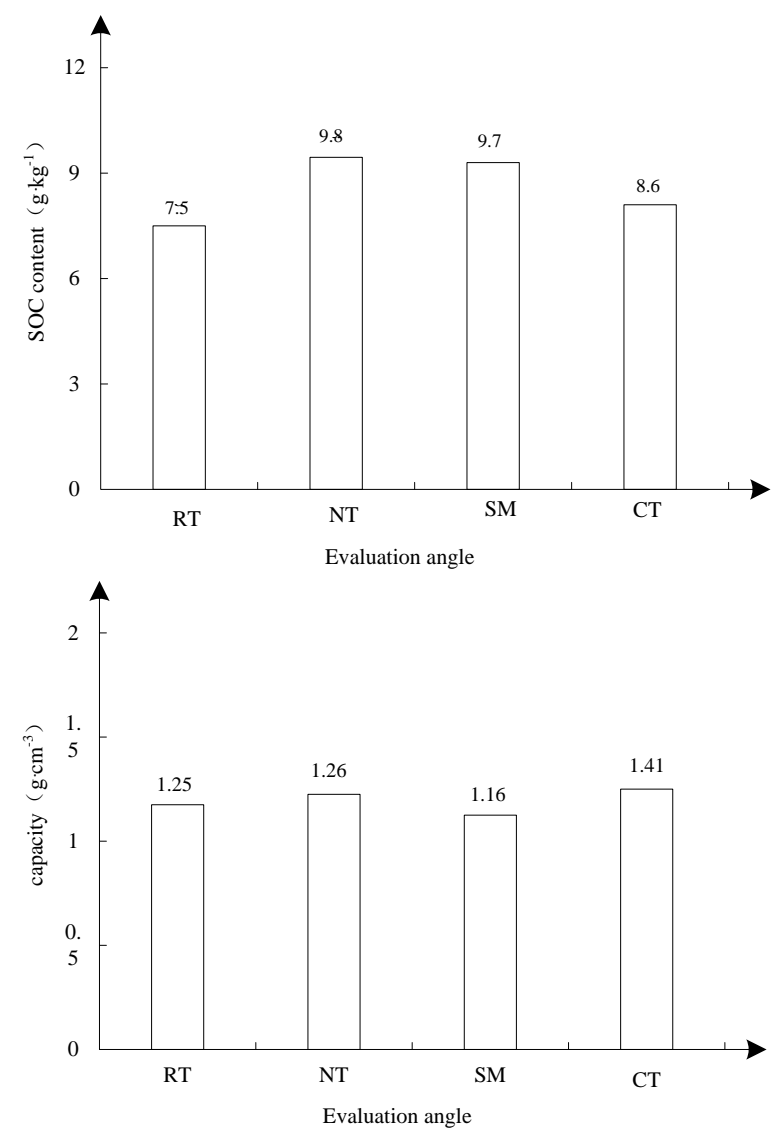


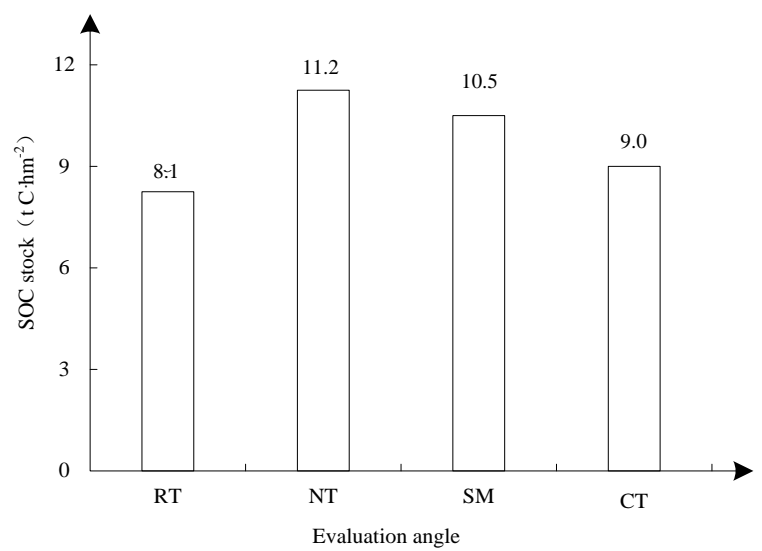

Figure 5. Effects of long-term tillage on soil organic carbon content, capacity and organic carbon storage

It can be seen from Figures 6 and 7 that the carbon sequestration and carbon sequestration rate can be used as characteristic parameters for the evolution of organic carbon.

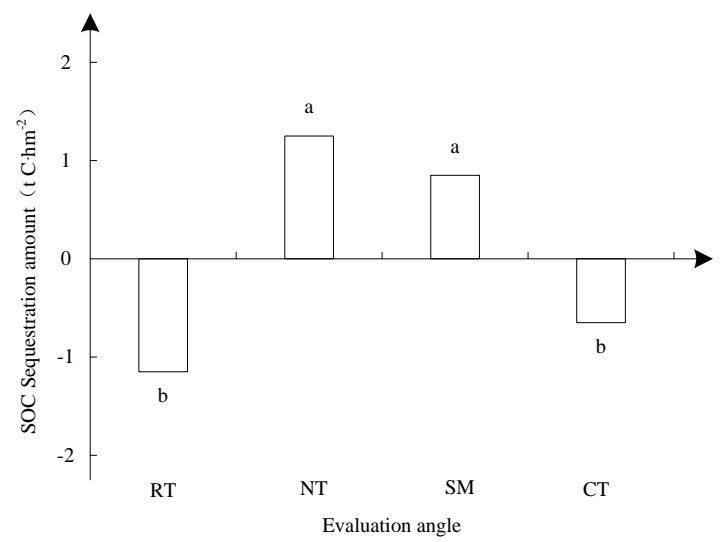

Figure 6. Carbon fixation in long term different tillage treatment

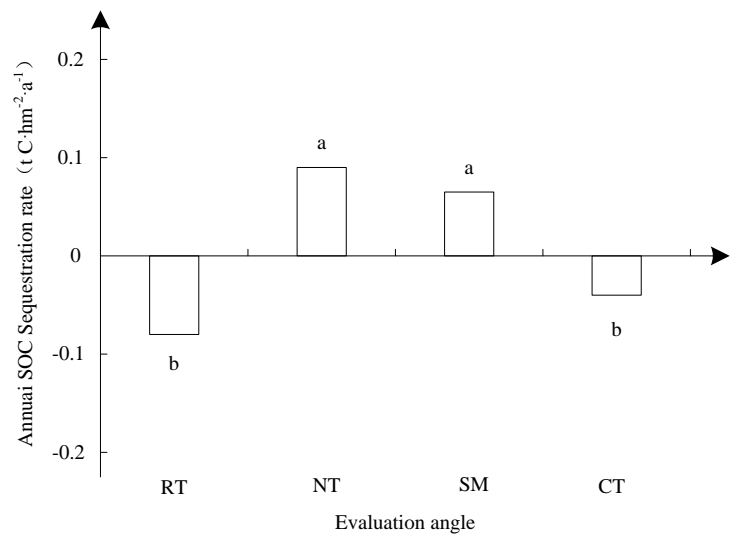

Figure 7. Carbon fixation rate of long term different tillage treatment 
This study showed that under 15 years of conservation tillage, the soil organic carbon content of no-tillage and deep pine treatment with straw mulching as the main feature showed the upward trend.

Taking the year of 2006-2014 as the influencing factor, the changes of soil organic carbon content in yellow soil paddy field were analyzed under the condition of no fertilizer and long-term fertilizer, respectively. In order to fully verify the effectiveness of the proposed method, the variance of the change of organic carbon content is calculated and counted, and the results are shown in Figure 8.

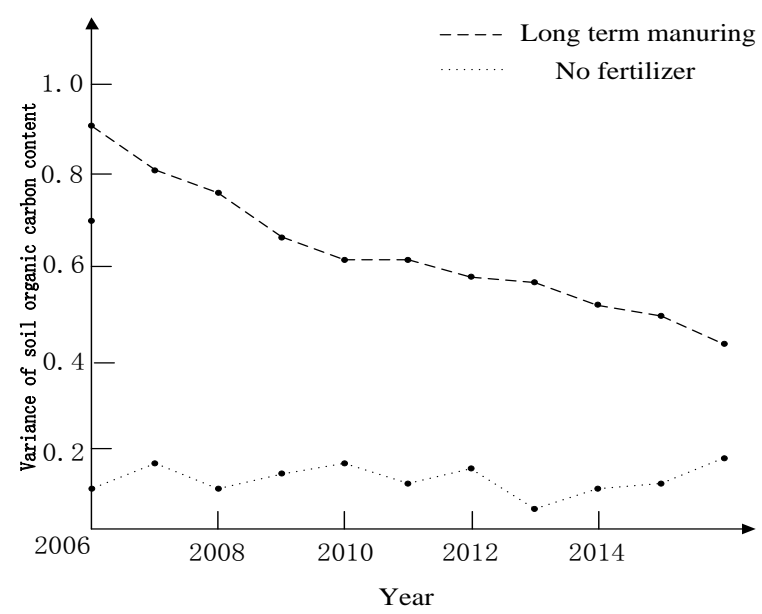

Figure 8. Variance of soil organic carbon content

Figure 8 shows that the variance of the change of organic carbon content is small under the condition of no fertilizer, and the influence of different years on the change of organic carbon content is small. Under the condition of long-term fertilizer, the variance of organic carbon content is larger, and the influence of different years on the change of organic carbon content is greater.

In order to further verify the effectiveness of the proposed method, the research accuracy of this method is compared with that of the traditional method, and the results are shown in Table 4.

Table 4. Comparison of research accuracy

\begin{tabular}{c|c|c}
\hline Number of experiments/times & Paper method (\%) & Traditional method (\%) \\
\hline 5 & 89 & 76 \\
10 & 88 & 75 \\
15 & 90 & 74 \\
20 & 92 & 72 \\
15 & 93 & 80 \\
\hline
\end{tabular}

The analysis Table 4 shows that the research accuracy of this method is obviously higher than that of the traditional method, which shows that the research method has some advantages. 


\section{Discussion}

\section{Effect of NPK on soil organic matter composition}

This study shows that in all treatments, the free active organic carbon belonging to high-activity organic carbon accounts for the relatively high proportion. It consists of unprotected coarse-grained organic carbon and fine-grained organic carbon, and is often used as one of the indicators of organic carbon change. Biochemically protected organic carbon and chemically protected organic carbon belong to the category of inert mineralbound organic carbon (Song et al., 2015), which has strong stability. No change in chemically protected organic carbon indicates that long-term application of chemical fertilizer is not conducive to the accumulation of chemically protected organic carbon. The reason is that chemically protected organic carbon is mainly composed of humus, and the input of organic matter by NPK fertilizer is not enough to make up for its mineralization loss. During the period of 2006-2014, there was no significant change in physical protection of organic carbon under NPK treatment, indicating that it is less affected by chemical fertilizers.

\section{Effect of single application of organic fertilizer on soil organic matter components}

In this study, compared with single application of chemical fertilizer, the SOC and organic carbon content of each component were significantly increased with the fertilization period, which fully indicated its positive effect on increasing SOC reserves. The reason is that the application of organic fertilizer can not only increase crop yield, but also increase the direct input of carbon. This PANDEY et al study also shows that long-term application of organic fertilizer can increase the content of high-activity organic carbon and mineral-bound organic carbon in soil (Madejón et al., 2016). This PANDEY et al study also showed that long-term application of organic fertilizer can increase the content of high-activity organic carbon and mineral-bound organic carbon in soil. In this study, the proportion of mineral-bound organic carbon in the treatment with single application of organic fertilizer decreased slightly. The reason may be that the amount of soil fungi is increased in this case, so that the clay particles are converted into micro-aggregate particles. It increases the amount of animal and plant residues and secretions in the free active organic carbon. Yan Xiaogang et al. shows that the proportion of physical protection organic carbon in fluvo-aquic soil is $5.0-8.9 \%$, which is mainly due to the physical protection of micro-aggregates, it reduces the decomposition of SOC by microorganisms and thus the effect of sequestering organic carbon.

\section{Effect of NPK combined with organic fertilizer on organic matter components}

The SOC content and annual variation of the MNPK treatment in this study are higher than 0.5MNPK treatment, which is consistent with most studies (Madejón et al., 2016). The SOC content mainly depends on the balance between the input and degradation of organic carbon, that is, the combination of constant organic fertilizer and chemical fertilizer. On the one hand, chemical fertilizer can increase microbial activity and increase crop root exudates.

On the other hand, organic fertilizer directly provides organic substances and promotes the increase of SOC. The study also shows that MNPK treatment improves the content of organic carbon in each component better than $0.5 \mathrm{MNPK}$ treatment, which 
is consistent with the results of Zhang Jingye and Liang Shuming (Bahr et al., 2015). Yan Xiaogang's research shows that the content of free-particle organic carbon increased significantly under MNPK treatment, and there are differences in the proportion of organic carbon in each component under the same management measures and different fertilizer application rates. 0.5MNPK and MNPK still show the largest proportion of free active organic carbon. Compared with $M$ treatment, their proportion of free active organic carbon is low. Because the long-term cooperation between NPK and organic fertilizers makes the non-protected active organic carbon form the stable Humin, it provides biochemical protection for organic carbon; it may also be that microbial metabolism promotes the accumulation of clay organic carbon.

\section{Evolution characteristics of SOC in yellow soil paddy field under long-term fertilization}

In this study, the SOC content shows the downward trend from 1995 to 2006. From 2006 to 2014, the SOC content under various conditions shows the very significant linear increase trend. This is due to changes in the farming system. Due to lack of water, the test site is changed to dry land during 2002-2006 and rice is replanted in 2007. The high permeability of dry land is conducive to the activity of soil microbes, resulting in the consumption of soil organic matter. The flooding and anoxic conditions of paddy fields inhibit their activities, which in turn is conducive to the accumulation of organic matter; on the other hand, paddy field conditions can effectively protect SOC. Other studies have also shown that the SOC content of paddy fields under the same conditions is significantly higher than that of dry land (Liu and Zhou, 2017).

\section{Effect of long-term fertilization on carbon-N ratio in paddy yellow soil}

Soil carbon-N ratio can reflect the coupling relationship between soil carbon and nitrogen, and is the important indicator for evaluating soil quality. The difference in soil carbon- $\mathrm{N}$ ratio between the fertilization treatments is not significant at around 12.3. This is consistent with the results of Luo Kun's research that the effect of fertilization measures on carbon- $\mathrm{N}$ ratio is not significant (Wander and Aref 2015). The soil carbonnitrogen ratio is mainly related to the degree of soil organic matter. The carbon-nitrogen ratio of fresh organic matter tends to be higher, and the carbon-nitrogen ratio decreases with the increase of humification degree. Therefore, while increasing nitrogen input, the return level of carbon and nitrogen should be also paid attention. Vigorously promote the application of organic fertilizer and straw returning to maintain the stable increase in soil carbon-N ratio.

\section{Carbon sequestration effect of conservation tillage}

On the contrary, the less tillage treatment without straw returning decreased by $10.7 \%$, which indicates that the conservation tillage of straw returning could increase soil organic carbon, while the no-tillage with reduced tillage frequency and intensity did not significantly improve organic carbon. Wang Chengji's research also shows that the organic carbon of conservation tillage with no increase in straw returning to the field is very small, and the no-tillage based on tillage management has great uncertainty on the accumulation of SOC in farmland. 


\section{Conclusions}

The results of this study indicate that the soil organic matter content of yellow loam paddy soil is still at low level, which has the large carbon sequestration potential and capacity. Free active organic carbon is the largest part of SOC. The combination of organic and inorganic fertilizers also significantly increased the unprotected free activity, physical protection and chemically protected organic carbon content of the soil, and the highest increase is achieved under the condition of constant organic-inorganic application. The effect of single application of chemical fertilizer on the increase of SOC content and total nitrogen content is relatively small. The alone application of organic fertilizer or organic and inorganic fertilizer could significantly increase the SOC content and total nitrogen content. When applying organic fertilizer, the application of nitrogen fertilizer is more conducive to soil carbon sequestration. When applying nitrogen fertilizer, it is more beneficial to soil nitrogen conservation and maintain proper carbon- $\mathrm{N}$ ratio and carbon- $\mathrm{N}$ coupling relationship. Therefore, the constant combination of organic and inorganic fertilizers is the most effective mode to increase soil organic carbon storage.

The organic carbon reserves of no-tillage and deep pine cover treatment is significantly higher than that of less tillage and traditional tillage, and the soil carbon sequestration increased significantly with the increase of cumulative carbon input. To maintain the stability of SOC reserves, the minimum of $2.4 \mathrm{t} \mathrm{C} \cdot \mathrm{hm}^{-2}$ carbon is required each year. Through long-term conservation tillage, the organic carbon storage of the soil and micro-aggregate in the high loess slope area is improved, which is the farmland management measure that is conducive to the increase of carbon in the soil.

\section{REFERENCES}

[1] Amelian, S., Manian, M., Abtahi, S. M., Goli, A. (2018): Moisture sensitivity and mechanical performance assessment of warm mix asphalt containing by-product steel slag. - Journal of Cleaner Production 176: 329-337.

[2] Bahr, E., Chamba-Zaragocin, D., Fierro-Jaramillo, N. (2015): Modeling of soil nutrient balances, flows and stocks revealed effects of management on soil fertility in south Ecuadorian smallholder farming systems. - Nutrient Cycling in Agroecosystems 101(1): 55-82.

[3] Cruz Campas, M., Villalba Villalba, A. G., Ramirez Leal, R. (2017): Editorial. - Revista Internacional De Contaminacion Ambiental 33(SI): I-I.

[4] Dietrich, A. L., Lind, L., Nilsson, C. (2014): The use of phytometers for evaluating restoration effects on riparian soil fertility. - Journal of Environmental Quality 43(6): 1916.

[5] Herencia, J. F., Maqueda, C. (2016): Effects of time and dose of organic fertilizers on soil fertility, nutrient content and yield of vegetables. - Journal of Agricultural Science 154(8): 1343-1361.

[6] Hu, H., Chen, X., Sun, Z. (2017): Effect of water flows on ship traffic in narrow water channels based on cellular automata. - Polish Maritime Research 24(SI): 130-135.

[7] Jiang, G., Xu, M., He, X. (2014): Soil organic carbon sequestration in upland soils of northern China under variable fertilizer management and climate change scenarios. Global Biogeochemical Cycles 28(3): 319-333.

[8] Kagawa, M., Matsubara, K., Kimura, K. (2014): Impacts of organic matter amendments on carbon and nitrogen dynamics in grassland soils. - Soil Biology and Biochemistry 68(1): 52-61. 
[9] Kintché, K., Guibert, H., Bonfoh, B. (2015): Long-term decline in soil fertility and responsiveness to fertiliser as mitigated by short fallow periods in sub-Sahelian area of Togo. - Nutrient Cycling in Agroecosystems 101(3): 333-350.

[10] Kunlanit, B., Vityakon, P., Puttaso, A. (2014): Mechanisms controlling soil organic carbon composition pertaining to microbial decomposition of biochemically contrasting organic residues: evidence from midDRIFTS peak area analysis. - Soil Biology and Biochemistry 76(1): 100-108.

[11] Li, S., Gu, X., Zhuang, J. (2016): Distribution and storage of crop residue carbon in aggregates and its contribution to organic carbon of soil with low fertility. - Soil and Tillage Research 155(2): 199-206.

[12] Li, Y., Yu, H., Chappell, A. (2014): How much soil organic carbon sequestration is due to conservation agriculture reducing soil erosion? - Soil Research 52(7): 717-726.

[13] Liu, C. A., Zhou, L. M. (2017): Soil organic carbon sequestration and fertility response to newly-built terraces with organic manure and mineral fertilizer in a semi-arid environment. - Soil and Tillage Research 172(X): 39-70.

[14] Madejón, P., Alaejos, J., García-Álbala, J. (2016): Three-year study of fast-growing trees in degraded soils amended with composts: Effects on soil fertility and productivity. Journal of Environmental Management 169(8): 18-26.

[15] Manjunatha, J. G., Deraman, M., Basri, N. H., Talib, I. A. (2018): Fabrication of poly (solid red a) modified carbon nano tube paste electrode and its application for simultaneous determination of epinephrine, uric acid and ascorbic acid. - Arabian Journal of Chemistry 11(2): 149-158.

[16] Naab, J. B., Mahama, G. Y., Koo, J. (2015): Nitrogen and phosphorus fertilization with crop residue retention enhances crop productivity, soil organic carbon, and total soil nitrogen concentrations in sandy-loam soils in Ghana. - Nutrient Cycling in Agroecosystems 102(1): 33-43.

[17] Ouyang, H., Hou, K., Wang, L., Peng, W. (2017): Optimization protocol for the microwave-assisted extraction of antioxidant components from Pinus elliottii needles using response surface methodology. - Bioresources 12(1): 478-494.

[18] Qiu, S., Xie, J., Zhao, S. (2014): Long-term effects of potassium fertilization on yield, efficiency, and soil fertility status in a rain-fed maize system in northeast China. - Field Crops Research 163(1): 1-9.

[19] Roy, S., Handique, G., Bora, F. R., Rahman, A. (2018): Evaluation of certain nonconventional plant based oils against red spider mite of tea. - Journal of Environmental Biology 39(1): 1-4.

[20] Sang, S. L., Shah, H. S., Awad, Y. M. (2015): Synergy effects of biochar and polyacrylamide on plants growth and soil erosion control. - Environmental Earth Sciences 74(3): 2463-2473.

[21] Song, Z. W., Zhu, P., Gao, H. J. (2015): Effects of long-term fertilization on soil organic carbon content and aggregate composition under continuous maize cropping in Northeast China. - Journal of Agricultural Science 153(2): 236-244.

[22] Wander, M. M., Aref, S. (2015): Long-term trends of corn yield and soil organic matter in different crop sequences and soil fertility treatments on the Morrow Plots. - Advances in Agronomy 62(08): 153-197.

[23] Wang, Y., Tang, J., et al. (2014): Aggregate-associated organic carbon and nitrogen impacted by the long-term application of fertilizers, rice straw, and pig manure. - Soil Science 179(10-11): 522-528.

[24] Wang, Y., Yang, Y., Shi, X., Mao, S., Shi, N., Hui, X. (2016): The spatial distribution pattern of human immunodeficiency virus/acquired immune deficiency syndrome in China. - Geospatial Health 11(2): 104-109.

[25] Wentzel, S., Schmidt, R., Piepho, H. P. (2015): Response of soil fertility indices to longterm application of biogas and raw slurry under organic farming. - Applied Soil Ecology 96(4): 99-107. 
[26] Zhang, F., Li, C., Wang, Z. (2016): Long-term effects of management history on carbon dynamics in agricultural soils in Northwest China. - Environmental Earth Sciences 75(1): $1-9$.

[27] Zhang, J. H., Wang, Y., Li, F. C. (2015): Soil organic carbon and nitrogen losses due to soil erosion and cropping in a sloping terrace landscape. - Soil Research 53(1): 87-96.

[28] Zhang, S., Pan, X., Wang, S., Yang, C., Gao, X., Wang, Z., Li, M., Ren, Z., Zheng, Q., Ma, W., Zhao, F., Qiao, Y. (2015): Knowledge of human papillomavirus vaccination and related factors among parents of young adolescents: a nationwide survey in China. Annals of Epidemiology 25(4): 231-235. 